\title{
Toward a Platform-Independent Acoustic Communications and Navigation System for Underwater Vehicles
}

\author{
Sarah E. Webster*, Ryan M. Eustice ${ }^{\dagger}$, Christopher Murphy ${ }^{\ddagger}$, Hanumant Singh ${ }^{\ddagger}$, Louis L. Whitcomb* $^{*}$ \\ * Department of Mechanical Engineering \\ Johns Hopkins University, Baltimore, MD 21218 \\ email: \{swebster,llw\}@jhu.edu \\ ${ }^{\dagger}$ Department of Naval Architecture and Marine Engineering \\ University of Michigan, Ann Arbor, MI, 48109 \\ email: eustice@umich.edu \\ ${ }^{\ddagger}$ Department of Applied Ocean Physics \& Engineering \\ Woods Hole Oceanographic Institution, Woods Hole, MA 02543 \\ email: \{cmurphy,hanu\}@whoi.edu
}

\begin{abstract}
This paper presents a platform-independent acoustic communication (Acomms) system that enables multiple nodes (any combination of underwater vehicles, surface ships, and fixed beacons) to simultaneously exchange data and calculate inter-node ranges with $\mathcal{O}(1 \mathrm{~m})$ accuracy. The Acomms system supports two types of communications: standard asynchronous acoustic communication and synchronous communication, which enables navigation based on inter-node ranges derived from the one-way travel-times of acoustic messages between nodes. The Acomms system hardware is implemented with a dedicated software program, Linux host computers, Woods Hole Oceanographic Institution (WHOI) Micro-Modems, and precision reference clocks. The acoustic communications software configures the modem, manages all acoustic communication traffic, and acts as an interface between the vehicle-specific software and the modems and clocks. The software and related hardware have been installed on the Woods Hole Oceanographic Institution vehicles Puma, Jaguar, and Nereus, and deployed in sea trials in the North Pacific and South Atlantic.
\end{abstract}

\section{INTRODUCTION}

Advances in underwater communication systems promise improved communication and connectivity for autonomous underwater vehicles. Acoustic communication systems are increasingly employed on autonomous underwater vehicles (AUVs), which have historically had limited telemetry when submerged. This paper describes the implementation of the Acoustic Communications (Acomms) system, a platformindependent system for combined communication and navigation of multiple underwater vehicles that integrates WHOI Micro-Modems [7], [8], a stand-alone software interface, and subsea precision clocks [5], [6]. A system architecture overview and results of recent field trials are reported.

The Acomms system enables both asynchronous communication between multiple underwater and surface vehicles and, when used in conjunction with precision clocks, synchronous communication and navigation. Both modes of operation are described in detail herein. While the communications and one-way travel time features are provided using the WHOI Micro-Modem, the concepts have been developed in a hardware independent framework and can be used with any acoustic system or combination of systems that includes bidirectional communications with synchronous transmission and precision time-tagged reception.

Multi-vehicle operations are motivated by the desire to collect richer data sets, i.e. increased spatial extent, spatial resolution, and/or variety of data types collected, while using less ship time. In addition, synchronous communication and navigation enables one or more vehicles to use a single, geo-referenced, moving beacon, e.g. the ship, to perform bounded-error navigation. Currently bounded-error navigation is achieved with the aid of systems such as long baseline navigation (LBL) that require external, fixed reference beacons, additional survey time, and have a range of only $5-10 \mathrm{~km}$. Using the ship as a reference beacon enables the vehicles to travel $\mathcal{O}(10-100 \mathrm{~km})$ limited only by speed and endurance.

The Acomms software and related hardware have been installed on the Woods Hole Oceanographic Institution vehicles Puma, Jaguar, and Nereus, and have been deployed in sea trials in the North Pacific and South Atlantic.

\section{A. Asynchronous Communication}

The majority of vehicles that use underwater modems operate the modem asynchronously: the modems are used to transmit data and send commands between nodes, where a node can be an underwater vehicle, a ship, or a fixed entity such as a mooring, without the need for precision or synchronized time-keeping among the nodes. The Acomms software, designed to operate symmetrically on all nodes, initializes the modem and issues a sequence of modem commands, defined by the user, to initiate data transmissions between nodes, transmit ranging pings, and interrogate acoustic navigation beacons. In addition, the Acomms software enables the user to specify modem configurations and ensures that the modem stays properly configured in the event of a vehicle or modem reboot.

The Acomms software provides basic format checking for messages sent to the modem, time-stamps and logs all 
modem communication traffic and Acomms related data, monitors the state of the modem, tracks message traffic and modem status, and reports modem statistics to the vehicle controller. The details of the Acomms software are discussed in detail in Section II-D.

\section{B. Synchronous Communication and Navigation}

In addition to asynchronous communication capabilities, the Acomms system enables synchronous communication and navigation when equipped with a precision time receiver. For synchronous communication, the computer of a subsea node is disciplined using a precision clock board that is synchronized to a GPS timeserver prior to the start of the dive. Topside nodes, i.e. nodes that are not submerged, are synchronized to a GPS timeserver via the Network Time Protocol (NTP).

Synchronous communication enables synchronous-clock one-way-travel-time (OWTT) navigation. OWTT navigation uses one-way travel times of acoustic messages to estimate range between two nodes, one of which has knowledge of its position in the world frame such as a vehicle or ship that is equipped with a GPS receiver [5], [6], [17]. OWTT synchronous navigation relies on acoustic broadcasts of data packets that contain the transmitter's position and the time at which the message was transmitted. Because the transmitter and receiver clocks are synchronized, the receiver can calculate the time-of-flight of the acoustic broadcast using the time-of-arrival of the message and the time-of-launch that is encoded in the data packet. Time-of-flight information combined with the acoustically encoded transmitter's position provides a range measurement from this known position in the world frame. Between range measurements the vehicle performs dead-reckoning navigation. For a more detailed treatment of OWTT navigation readers are referred to [5], [6], [17].

The Acomms software supports OWTT navigation through a message packing function that precisely controls the timing of when a message is provided to the modem as specified in [10] and can thus properly anticipate and encode the time-oflaunch of the data packet. The Acomms software also ensures that the modem's internal clock, which is used to measure the time-of-arrival of messages, is properly disciplined.

In addition to enabling OWTT navigation, synchronous communication provides further advantages over asynchronous communication by making it possible to accurately predict acoustic transmissions of other nodes, thereby enabling synchronized time-division multiple access (TDMA) cycles among nodes with multiple masters. Typically, to avoid collision of acoustic messages, a single node is designated as the master that commands data transmissions for all nodes in a deployment. Synchronous communication eliminates the need for a single master node because messages originating at different nodes can be scheduled a priori to not overlap. We made extensive use of this feature in our field trials with a two-node deployment (a vehicle and a ship) as described in Section III. While desirable to have the majority of acoustic transmissions initiated by the vehicle, it is also necessary to retain the ability to interject messages from the ship, such as an abort message that commands the vehicle to return to the surface. Using synchronous communication we know the exact timing of the vehicle's sequence of acoustic transmissions and can reliably predict when the acoustic channel is clear for transmission from the ship. We can further exploit this functionality to enable on-the-fly switching between different modem modes (e.g. frequency band, modulation method, bandwidth, and bitrate) as described in more detail in section II-A, which requires simultaneously reconfiguring both the transmitting and receiving modems.

Acoustic modem drivers previously reported by the authors and others for synchronous navigation, such as the modem drivers employed on the MIT autonomous surface vehicles, [4], and the WHOI Seabed vehicles, [5], [6], are not portable due to the tight integration of these modem drivers into the vehicle-specific application code of their respective vehicle control and navigation systems. In contrast, the Acomms software reported herein is portable, employs a vehicle-independent interface based on UDP messages, runs as a stand-alone daemon on a host Linux CPU, and operates symmetrically on all node types - e.g. underwater vehicles, fixed beacons, and surface ships.

\section{System Architecture}

The architecture of the Acomms system in a typical twonode setup is depicted in Figure 1, where the vehicle is referred to as the subsea node and the ship is referred to as the topside node. Topside the Acomms software runs on a laptop running Ubuntu Linux and communicates with the ship-board modem via the network using UDP messages through a MOXA ${ }^{\mathrm{TM}}$ serial device server. We use a Meinberg GPS/NTP shipboard timeserver. The Meinberg also supplies a pulse-per-second (PPS) signal to the topside modem, which consists of a $1 \mathrm{~Hz}$ square wave that has its rising edge synchronized with the start of the second. Subsea the Acomms software runs on the main vehicle stack, also running Ubuntu Linux, and communicates with the modem over a serial connection. Acomms communicates with the vehicle's controller and navigation processes over the local network using UDP messages. At present, no commercially available precision clocks (such as the Meinberg noted above) are suitable for use on small AUVs due to power and size constraints. To address this, we developed the PPSBoarda small, comparatively low power, precision clock board suitable for AUV applications [5], [6]. The PPSBoard on the vehicle provides a PPS signal to the vehicle's modem and provides PPS and NMEA time signals to the vehicle's on-board NTP server.

For asynchronous communication the Acomms system requires an acoustic underwater modem, a transducer and a host computer at each node. In the field trials presented here we use the Woods Hole Oceanographic Institution (WHOI) Acoustic Micro-Modem. Synchronous communication additionally requires that each node's computer be synchronized within an acceptable tolerance for the duration of the mission. We accomplish this using the PPSBoard, 


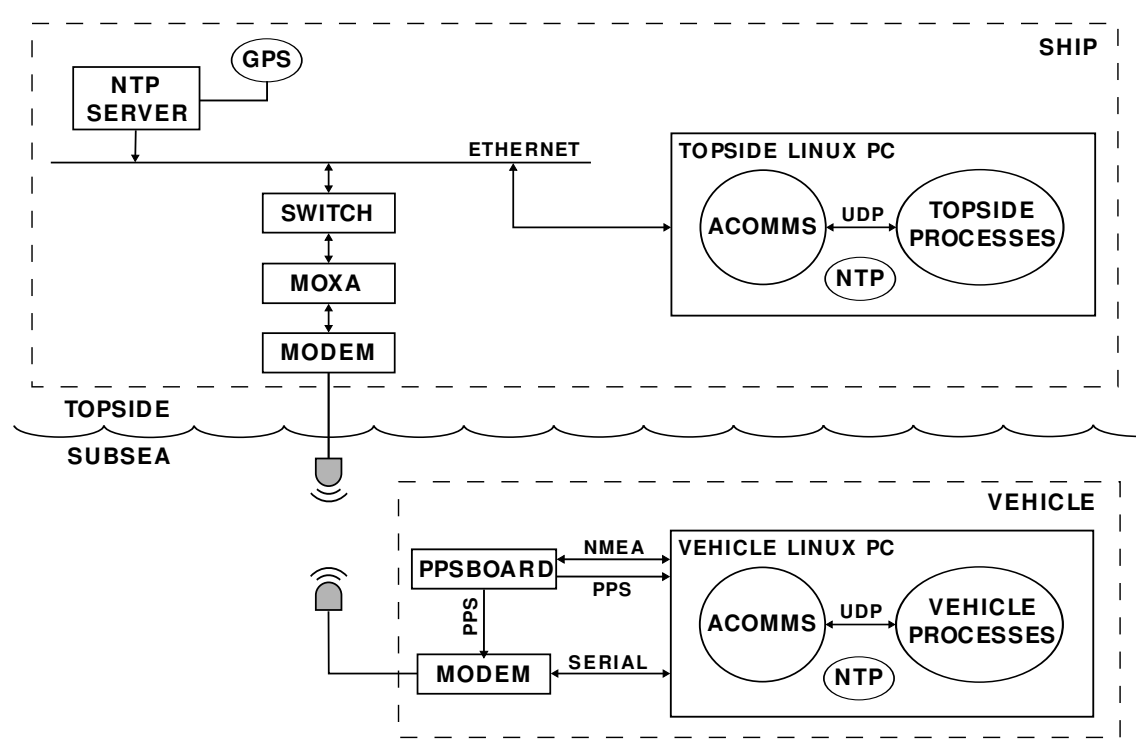

Fig. 1. Typical sea-going architecture for a two-node deployment of the Acomms system.

which is a vehicle-based precision clock board, and a topside NTP timeserver, both described below.

\section{A. WHOI Micro-Modem}

The WHOI Micro-Modem is an underwater acoustic modem capable of encoding data into acoustic data packets that it transmits through the water column [7], [8]. All Micro-Modems are able to receive frequency-shift keyed (FSK) encoded acoustic messages. With the addition of a co-processor board, the Micro-Modems are also able to receive phase-shift keyed (PSK) encoded messages. Minipackets (32 bits long) take $840 \mathrm{~ms}$ to transmit. Data packets (32 bytes long) take 4 seconds to transmit. The range of the Micro-Modem varies with transmit frequency and the acoustic channel characteristics (horizontal/shallow channel versus vertical/deep channel). During one trial the range of a $10 \mathrm{kHz}$ carrier signal was reported to be roughly $4 \mathrm{~km}$ using FSK encoded messages [12], though the range will vary with the conditions and the experimental setup.

The Micro-Modem employs its own internal clock to calculate the travel-time of ranging pings and replies from acoustic navigation beacons, and the time-of-arrival of acoustic messages. When the modem is in Synchronous Navigation (SNV) mode, as described in [10], the modem's clock can be synchronized to a PPS signal using a NMEA clock message from the host. Once synchronized, the time-of-arrival (TOA) of each arriving message is reported to have an accuracy of \pm $125 \mu$ s with respect to the PPS signal [8]. The accuracy of the PPS signals used topside and subsea are discussed in Sections II-B and II-C. In SNV mode, all transmitted messages are initiated by the modem within $\pm 10 \mu$ s of the rising edge of the PPS signal, referred to as the top-of-the-second [10].

\section{B. PPSBoard}

The PPSBoard provides a stable time reference that keeps the undersea vehicle's CPU clock and the vehicle's modem synchronized with the topside clock throughout the mission. The PPSBoard, described in detail in [5] and [6], was developed by the authors Eustice and Whitcomb to provide a free-running, precision timing reference for use subsea that can be synchronized to a GPS timing signal. The PPSBoard supplies a PPS signal and a NMEA-formatted clock message naming the upcoming second to the vehicle computer. The PPSBoard, which is synchronized to a GPS signal while the vehicle is on deck, is used to discipline the vehicle CPU's NTP server. The drift characteristics of the PPSBoard $(\sim 1$ ms drift over 14 hours) ensure that the error introduced in the estimated range between the ship and the vehicle due to the relative drift between the two clocks is small: $\sim 1.5$ $\mathrm{m}$ error over 14 hours in the range between the ship and the vehicle. In addition to supplying a timing reference to the host computer, the PPSBoard also supplies a PPS signal to the Micro-Modem to enable its synchronous navigation mode described above.

\section{Topside NTP Timeserver}

The Meinberg GPS/NTP timeserver, which we use to provide a stable, shipboard timing reference, is a Stratum1 NTP timeserver. The topside computer stays synchronized with the timeserver over the network via NTP. The Meinberg also supplies a PPS signal to the topside modem. The PPS signal from the Meinberg is accurate to within $10 \mu$ s [11].

\section{Acomms Software}

The Acomms software is a multi-threaded program written in $\mathrm{C} / \mathrm{C}++$ that executes a state machine consisting of three sections: a modem initialization section, a TDMA sequence of commands, and a clock watchdog. The Acomms software is designed to run as a stand-alone process, in either the foreground or the background, communicating with the modem and other processes via serial or network connections. The Acomms software is also able to run as a daemon. On 


\begin{tabular}{c||c||c}
\hline Command & Size & Addt'l Info \\
\hline \hline Configuration & n/a & supports all available cfgs \\
\hline Ranging Ping & 32 bits & return owtt between nodes \\
\hline Mini-Packet & 32 bits & user specified codes (Abort) \\
\hline Cycle-Init & 32 bits & initiates data tx \\
\hline Data Packet & $32-2048$ bytes & varies by encoding type \\
\hline LBL & $\mathrm{n} / \mathrm{a}$ & listen on 4 freq \\
\hline PAUSE & $\mathrm{n} / \mathrm{a}$ & see Section II-D.3 \\
\hline VLPAUSE & $\mathrm{n} / \mathrm{a}$ & see Section II-D.3 \\
\hline
\end{tabular}

Fig. 2. TDMA Cycle Command Summary

Nereus, the Acomms daemon is started during the host computer boot-up process to ensure that the daemon is always running even in the event that the vehicle computer reboots. The Acomms software is designed to act as a transport layer between the host computer and the modem, passing through all message traffic in both directions. All communications with the modem as well as various statistics on messages transmitted and received are time-stamped and logged. In addition, the Acomms software enables synchronous communication and navigation as described below.

1) $I / O$ : The Acomms software allows the user to specify the modem and host computer connections. The Acomms software supports both serial I/O connection and network I/O connections. Network I/O connections use UDP and can either broadcast or unicast to a specified UDP port. A typical setup uses a serial connection to the modem on the vehicle and a network connection to the topside modem. The software typically communicates with the vehicle control and navigation processes over the network. The software is also able to route specific types of modem messages to different processes. For example we have setup one network I/O thread to communicate with the main vehicle process and a second network I/O thread to communicate with the navigation process.

2) Modem Initialization: The Acomms software has a user-configurable initialization file that enables any of the WHOI Micro-Modem supported configurations to be specified. These configuration are sent to the modem when the Acomms process is started and every time the Acomms process receives a message from the modem indicating that the modem has rebooted in order to ensure that the modem stays properly configured.

3) TDMA: The Acomms software supports a userconfigured TDMA cycle of modem commands that is executed continuously except when interrupted by the modem initialization process or the clock watchdog. The TDMA cycle is used to command the modem to transmit acoustic messages, interrogate long baseline (LBL) beacons or change selective modem configurations such as the transmission frequency and bandwidth on the fly. Figure 2 shows the TDMA commands currently available in the Acomms software.

The commands PAUSE and VLPAUSE are special TDMA commands that pause the TDMA cycle before continuing to the next entry. PAUSE stops the state machine for a specified number of seconds, VLPAUSE pauses the state machine for a variable length of time in order to restart the state machine at an exactly-specified interval (e.g. at the beginning of every even minute). These commands can be used to insert time into the TDMA cycle so that the acoustic channel is clear for the modem to receive messages initiated at another node and, in the case of VLPAUSE, to synchronize the state machine with the vehicle clock.

Each entry in the TDMA cycle has an associated timeout period and a retry flag, such that if the step is not successfully completed by the end of the timeout period, the state machine will either move forward or resend the current messages as dictated by the retry flag. The Acomms software TDMA cycle is designed such that upon the successful completion of an entry in the state machine, the software can either proceed directly to the next entry, or it can wait for the full timeout specified for that entry. For operations where higher message transmission rates are desired, the former is used. For operations where it is desirable to keep the TDMA cycle synchronized to the clock, the latter, in combination with a VLPAUSE, is used.

4) SNV Mode and Clock Watchdog: In order for the Acomms software to support the Micro-Modem's synchronous navigation (SNV) mode, the modem's clock must be initialized and monitored. This is accomplished by sending appropriately-timed clock messages to the modem in conjunction with the PPS signal as described in [10]. The state machine sets the clock when Acomms is started, after every modem reboot, and whenever the clock watchdog is triggered by one of several indications that the modem clock needs to be set.

When the modem is in SNV mode, messages initiated by the modem are transmitted at the top-of-the-second, triggered by the rising edge of the PPS signal. The Acomms software monitors the timing of messages sent to the modem to ensure that the messages are provided adequately ahead of the top-of-the-second, as specified in [10], so that they can be transmitted at the top of the second.

One potential pitfall of SNV mode is that in the event of the loss of the PPS signal, no acoustic messages will be initiated by the modem. To prevent a vehicle from loosing all acoustic communications in this situation, a userconfigurable timeout is provided such that after a given number of seconds without the PPS signal the state machine will send a command to take the modem out of SNV mode.

5) Support for OWTT Navigation: To enable one-way travel-time synchronous navigation as described in Section $\mathrm{I}-\mathrm{B}$, the name of the top of the second at which a data packet will be transmitted must be encoded within the data packet. Because the Acomms process controls the timing of messages provided to the modem as described in Section II-D.4, the Acomms process anticipates the time-of-launch of a data packet and over-writes a designated byte in the data packet's payload with the name of the anticipated timeof-launch. This is the only instance in which the Acomms process will modify a message sent to the modem from the host process instead of simply passing it through. 


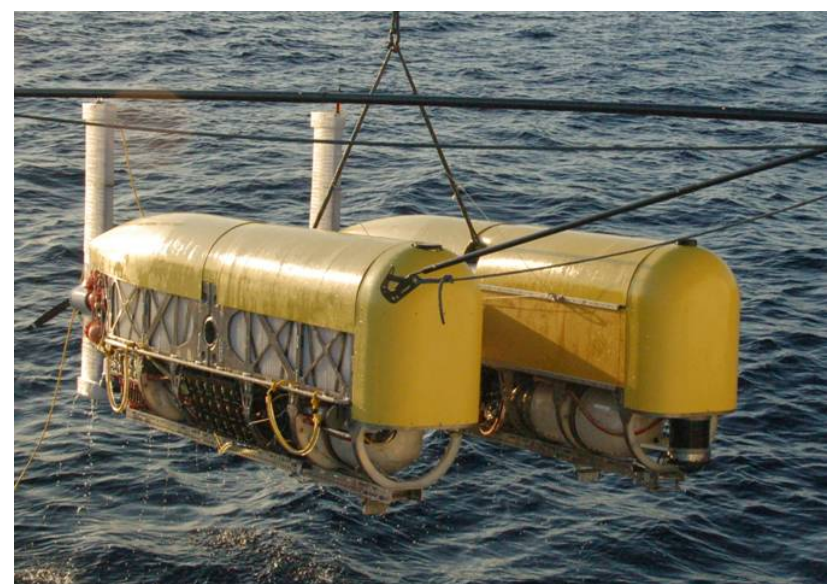

Fig. 3. The hybrid remotely operated vehicle Nereus configured as an AUV.

\section{FIELD RESUlts}

The Acomms system has been deployed successfully during field trials of the hybrid remotely operated vehicle (HROV) Nereus near Hawaii and on the Puma and Jaguar AUVs during an expedition to the southern Mid-Atlantic Ridge. On June 1, 2009 Nereus completed its first 10,900 $m$ depth dives in the Challenger Deep of the Mariana Trench, in which the Acomms software managed all acoustic communications. A description of the Nereus system and the Mariana Trench deployment is reported in [1]. An analysis of acoustic communication performance with variations in modulation method (FSK and PSK), frequency, bandwidth, and bitrate is reported in [13]. We summarize herein the Nereus field trials near Hawaii and the southern Mid-Atlantic Ridge expedition, including the typical topside and subsea setup used for both, and salient results.

\section{A. Asynchronous Communication Field Trial}

The first field trial of the Acomms system was in November 2007 near the coast of Hawaii on the HROV Nereus where it was used for asynchronous communication between the vehicle and the ship. Operations were conducted from the R/V Kilo Moana, a 185' small waterplane area, twin hull (SWATH) vessel operated by the University of Hawaii. Figure 3 shows Nereus in its AUV configuration being lowered into the water from the R/V Kilo Moana.

Nereus has an EDO Straza SP23 transducer mounted at the forward end of the starboard hull facing upwards. A second EDO Straza SP23 transducer was lowered from the stern of the ship, facing downwards, in a baffled cage to reduce the ambient acoustic noise. During initial tests the transducer was lowered from the ship and held 1-2 meters below the surface of the water to keep it clear of the ship's propellers and other gear in the water. Later a bridle was used to reduce side-to-side motion and position the transducer 3-4 meters below the surface of the water. During two of the dives Benthos transponders were also lowered off of the stern of the ship to test the modem's LBL functionality, though LBL beacons were not deployed at the site.

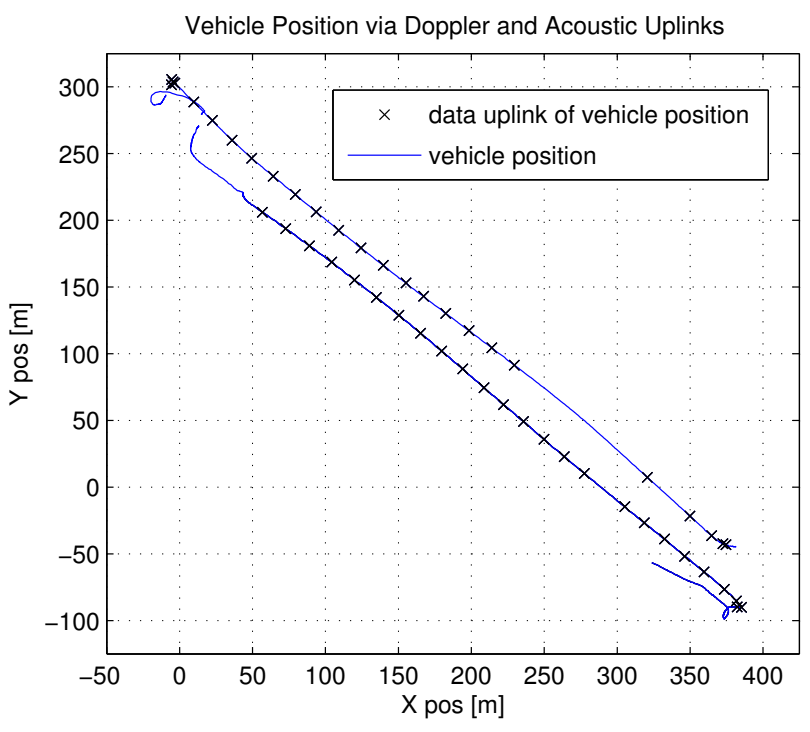

Fig. 4. Real-time acoustically-reported vehicle position overlaid on vehicle trackline.

The Acomms software was running on the vehicle in both ROV and AUV mode. When the vehicle was in ROV mode, the ship's Acomms software was typically designated as master using a state machine cycle consisting of a ranging ping to the vehicle, a request for a data packet to be transmitted from the vehicle to the ship, and an LBL ping if the LBL transducers were in the water. When the vehicle was in operation as an AUV, the Acomms software on the vehicle was typically designated as master using a state machine cycle consisting of a data packet transmitted from the vehicle to the ship and a pause to allow for messages to be transmitted from the ship to the vehicle if necessary.

The data packets transmitted from the vehicle to the ship consisted of the state and health of the vehicle, including location, speed, battery health, and the current goal or action. There was no LBL ping because the LBL beacons were not deployed during the AUV portion of the trials. All messages were FSK-encoded. The synchronous navigation mode was not employed because the PPSBoard was not installed on the vehicle at that time.

During the cruise three successful ROV dives were completed to a maximum depth of $2257 \mathrm{~m}$, with a total bottom time of $7 \mathrm{~h} 38 \mathrm{~min}$. As an AUV the vehicle completed multiple shallow dives over a period of $11 \mathrm{~h} 33 \mathrm{~m}$. The vehicle's maximum depth as an AUV was $22 \mathrm{~m}$ with $12 \mathrm{~min}$ of bottom time [2], [19]. While the vehicle was submerged, it transmitted data packets containing vehicle status and health information, including estimated position. Figure 4 shows the position data decoded from acoustically-transmitted status message overlaid on the full vehicle trackline retrieved after the conclusion of the dive. The acoustically-reported data, received in real-time, allowed us to monitor the vehicle's progress while it was underway, a valuable addition to our suite of tools. In addition to receiving vehicle status updates in real-time during a mission, we successfully tested an acoustic abort, where we sent an abort code to the vehicle over the Micro-Modems, which commands the vehicle to 


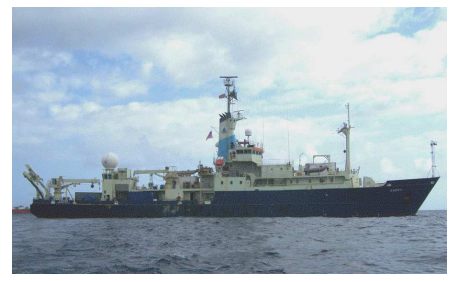

(a)

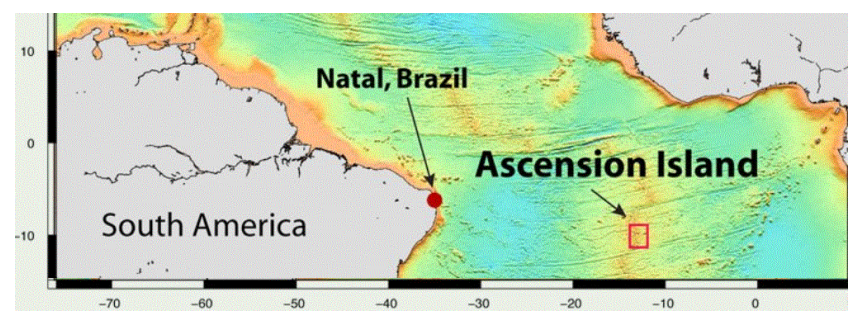

(c)

Fig. 5. (a) R/V Knorr (b) AUV Puma (c) The survey site is shown by the red box northeast of Ascension Island on the southern Mid-Atlantic Ridge.

drop weights and return to the surface.

\section{B. Synchronous Communication and Navigation Field Trial}

The second field trial of the Acomms system was conducted in January 2008 during engineering trials for methods for locating and mapping new hydrothermal vents on the southern Mid-Atlantic Ridge. Operations were conducted off of the R/V Knorr using the Puma and Jaguar AUVs. The survey site is located near $04^{\circ} \mathrm{S} 12^{\circ} \mathrm{W}$ in a deep nontransform discontinuity whose maximum depth exceeds 4000 $\mathrm{m}$ [9]. Figure 5 shows the ship R/V Knorr, the AUV Puma and a map showing the site of operation.

Each vehicle has a upward-facing ITC-3013 transducer mounted on the lower hull forward of the forward vertical yellow stanchion. A second ITC-3013 was lowered over the side of the ship 3-6 m below the surface of the water facing downward. Three LBL transducers were deployed at the site. The Micro-Modem was used to interrogate the LBL transducers and return travel times to the navigation process on the vehicle. The Acomms software running on the vehicle was designated as the master. All modem communication were FSK-encoded. Both vehicles also had PPSBoards installed, which allowed us to to synchronize the vehicle clock with the topside clock.

Acoustic ranges and vehicle navigation data collected during Dive 03 with Puma were used in post-processing to test the one-way travel-time synchronous navigation techniques described in Section I-B. Dive 03 lasted 21 hours, of which 9 hours were spent doing a gridded survey $200 \mathrm{~m}$ above the bottom. Using vehicle-to-ship ranges from the time-offlight of acoustic messages and the vehicle inertial sensor data, the estimated vehicle trajectory was calculated using the synchronous navigation technique. Figure 6 shows this trajectory compared with the LBL fixes of vehicle position.

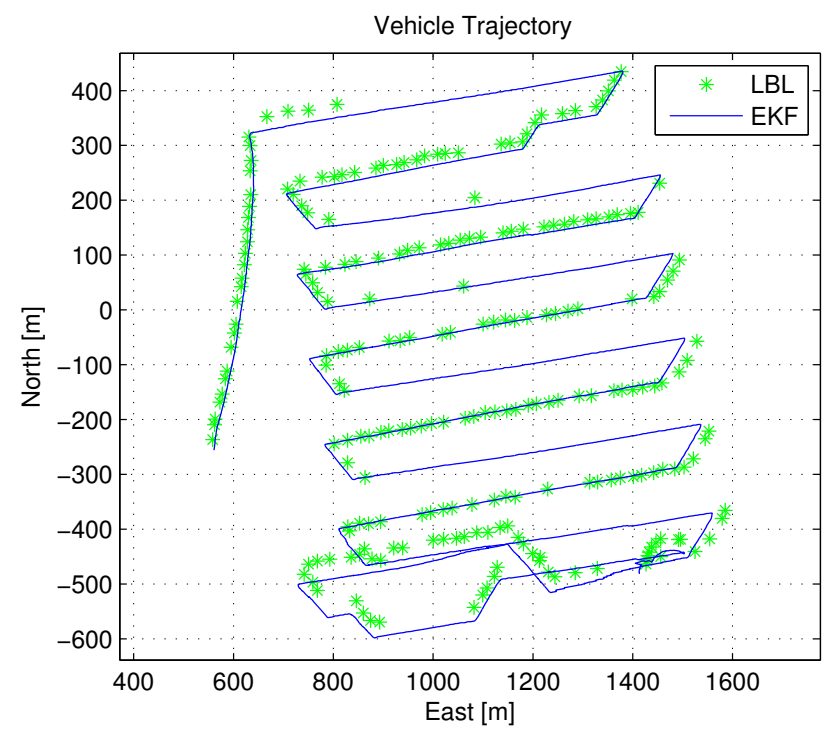

Fig. 6. Results of an EKF-based one-way travel-time navigation algorithm in post-processing using modem-derived ranges.

An approximately $3.5^{\circ}$ heading offset between the Doppler velocity $\log$ and the gyrocompass was estimated during postprocessing of the navigation data, which is calibrated for in the EKF results. LBL fixes were largely unavailable on tracklines where the vehicle was moving to the East, as shown in Figure 6, which suggests that the modem transducer may have been shadowed from the LBL beacons when the vehicle was on that heading.

We found that the vehicle modem had difficulty decoding messages received when the vehicle was driving to the bottom and at depth, possibly due to the location of the modem transducer on the lower hull where it was potentially shadowed from the ship or electrical or acoustic noise from the vehicle thrusters. The successful throughput of messages was asymmetric and depended on the type of message (32bit mini-packet versus full 32-byte data packet). For the dive shown here, we found that $39 \%$ of mini packets were successfully transmitted from the vehicle to the ship, whereas mini-packets received from the ship to the vehicle were successfully received only $22 \%$ of the time. The successful throughput of 32-byte data packets is predicated on the success of the mini-packets: for a 32-byte message to be successfully received, a type of mini-packet called a cycleinit must successfully be received first. Because the vehicle was designated master, all cycle-inits originated from the vehicle. Thus, the maximum percent of data packet transmissions possible is limited by the $39 \%$ success rate of vehicleto-ship mini-packets. Of the data transmissions that had successful cycle-inits, $59 \%$ of the data packets transmitted by the vehicle to the ship were successfully received and $25 \%$ of the ship-to-vehicle data packets were successfully received. This results in an over-all success rate of $23 \%$ for vehicleto-ship data packets and only $9.5 \%$ for ship-to-vehicle data packets. In addition to their sparsity, the messages received at the ship had time-of-flights that were largely inconsistent with the the time-of-flights of messages received at the ship. The cause of this discrepancy is still under investigation. The 
percentages presented here are based on a total of $\sim 2500$ mini-packets (including ranging pings and cycle-inits) and $\sim 900$ FSK-encoded data packets transmitted between the vehicle and the ship.

\section{CONCLUSIONS}

The Acomms system has been successfully installed on several ships and AUVs and utilized to manage all acoustic communications during two oceanographic expeditions. We successfully employed the Acomms system in the context of asynchronous communication in a two-node deployment to keep the modem properly configured, send and receive acoustic messages (both 32-bit mini-packets and 32-byte data packets), and communicate with the vehicle controller and navigation processes. In addition, the vehicle's Acomms system successfully received and responded to acoustic Abort commands sent from the ship.

During synchronous communication field trials, we again employed the Acomms system in a two-node deployment. In addition to accomplishments similar to those from the asynchronous communication trials, we successfully utilized the Acomms system to keep the host clocks at different nodes synchronized and the modem clocks synchronized to their respective host clocks. The Acomms system successfully kept the state machines at different nodes synchronized and successfully encoded OWTT navigation packets to enable the calculation of one-way travel times. The Acomms system demonstrated the ability to gracefully drop out of synchronous navigation (SNV) mode in the event of a loss of PPS while continuing to function. In addition we successfully used the Acomms systems to interrogate long baseline (LBL) acoustic navigation beacons and pass the resulting information to the navigation process.

\section{ACKNOWLEDGMENTS}

The authors are grateful for Micro-Modem support from current and former members of the WHOI Acoustic Communications Group including Keenan Ball, Lee Freitag, Matthew Grund, and Sandipa Singh. We are grateful to Clay Kunz and Giancarlo Troni for their help daemonizing the Acomms software. The authors would also like to thank Chris Taylor, John Bailey, and the entire Nereus team for their help implementing the hardware for the Acomms system on Nereus.

This work was supported by the National Science Foundation under NSF awards ATM-0427220 and ATM-0428122. The Nereus project was supported by the National Science Foundation under award OCE-0334411, the Office of Naval Research under work order N0001409WX20051, the National Oceanic and Atmospheric Administration under award NA04OAR4300168, the Woods Hole Oceanographic Institution, and the Russell Family Foundation.

\section{REFERENCES}

[1] A. D. Bowen, D. R. Yoerger, C. Taylor, R. McCabe, J. Howland, D. Gomez-Ibanez, J. C. Kinsey, M. Heintz, G. McDonald, D. Peters, J. Bailey, T. Shank, L. L. Whitcomb, S. C. Martin, S. E. Webster, M. V.
Jakuba, C. Young, J. Buescher, B. Fletcher, P. Fryer, and S. Hulme, "Field trials of the Nereus hybrid underwater robotic vehicle in the challenger deep of the mariana trench," in Proc. IEEE/MTS OCEANS Conf. Exhib., Biloxi, MS, Oct 2009, accepted, To Appear.

[2] A. D. Bowen, D. R. Yoerger, C. Taylor, R. McCabe, J. Howland, D. Gomez-Ibanez, J. C. Kinsey, M. Heintz, G. McDonald, D. B. Peters, B. Fletcher, C. Young, J. Buescher, L. L. Whitcomb, S. C. Martin, S. E. Webster, and M. V. Jakuba, "The Nereus hybrid underwater robotic vehicle for global ocean science operations to $11,000 \mathrm{~m}$ depth," in Proc. IEEE/MTS OCEANS Conf. Exhib., Quebec, Sept 2008.

[3] A. Brandt and D. Ron, Multilevel optimization in VLSICAD, ser. Combinatorial Optimization. Boston, MA: Kluwer Academic Publishers, 2003, vol. 14, ch. Multigrid solvers and multigrid optimization strategies, pp. 1-69.

[4] J. Curcio, J. Leonard, J. Vaganay, A. Patrikalakis, A. Bahr, D. Battle, H. Schmidt, and M. Grund, "Experiments in moving baseline navigation using autonomous surface craft," in Proc. IEEE/MTS OCEANS Conf. Exhib., Washington, D.C., Sep. 2005, pp. 730-735 Vol. 1.

[5] R. M. Eustice, L. L. Whitcomb, H. Singh, and M. Grund, "Recent advances in synchronous-clock one-way-travel-time acoustic navigation," in Proc. IEEE/MTS OCEANS Conf. Exhib., Boston, MA, USA, Sep. 2006, pp. 1-6.

[6] _ - "Experimental results in synchronous-clock one-way-travel-time acoustic navigation for autonomous underwater vehicles," in Proc. IEEE Intl. Conf. Robot. Auto., Rome, Italy, Apr. 2007, pp. 4257-4264.

[7] L. Freitag, M. Grund, J. Partan, K. Ball, S. Singh, and P. Koski, "Multi-band acoustic modem for the communications and navigation aid AUV," in Proc. IEEE/MTS OCEANS Conf. Exhib., Washington, D.C., Sep. 2005, pp. 1080-1085.

[8] L. Freitag, M. Grund, S. Singh, J. Partan, P. Koski, and K. Ball, "The WHOI micro-modem: an acoustic communications and navigation system for multiple platforms," in Proc. IEEE/MTS OCEANS Conf. Exhib., Washington, D.C., Sep. 2005, pp. 1086-1092.

[9] C. German, S. Bennett, D. Connelly, A. Evans, B. Murton, L. Parson, R. Prien, E. Ramirez-Llodra, M. Jakuba, T. Shank, D. Yoerger, E. Baker, S. Walker, and K. Nakamura, "Hydrothermal activity on the southern mid-atlantic ridge: Tectonically- and volcanically-controlled venting at 4-5s," Earth and Planetary Science Letters, vol. 273, no. 3-4, pp. 332 - 344, 2008. [Online]. Available: http://www.sciencedirect.com/science/article/B6V61-4SXP6TF1/2/976b220c0df55ef271a38c9c24f2c5a8

[10] M. Grund, J. Partan, P. Koski, and L. Freitag, "Synchronous navigation with the micro-modem," WHOI, Tech. Rep., 2005, document Revision: D.

[11] Meinberg LANTIME/GPS Manual: EXT 1HE V4, Meinberg Funkuhren GmbH \& Co. KG, Bad Pyrmont, Germany, May 2004.

[12] S. Singh, M. Grund, B. Bingham, R. M. Eustice, H. Singh, and L. Freitag, "Underwater acoustic navigation with the WHOI micromodem," in Proc. IEEE/MTS OCEANS Conf. Exhib., Boston, MA, Sep. 2006.

[13] S. Singh, S. E. Webster, L. Freitag, L. L. Whitcomb, K. Ball, J. Bailey, and C. Taylor, "Acoustic communication performance of the whoi micro-modem in sea trials of the Nereus vehicle to 11,000 m depth," in Proc. IEEE/MTS OCEANS Conf. Exhib., Biloxi, MS, Oct 2009, accepted, To Appear.

[14] S. E. Webster, Archaeological Oceanography. Princeton, NJ: Princeton Press, 2008, ch. The development of excavation technology for remotely operated vehicles, pp. 41-64.

[15] S. E. Webster, R. M. Eustice, C. Murphy, H. Singh, and L. L. Whitcomb, "Toward a platform-independent acoustic communications and navigation system for underwater vehicles," in Proc. IEEE/MTS OCEANS Conf. Exhib., Biloxi, MS, Oct 2009, accepted, To Appear.

[16] S. E. Webster, R. M. Eustice, H. Singh, and L. L. Whitcomb, "Advances in single-beacon one-way-travel-time acoustic navigation for underwater vehicles," IEEE J. Oceanic Eng., In Preparation.

[17] _ _ "Preliminary deep water results in single-beacon one-way-traveltime acoustic navigation for underwater vehicles," Intelligent Robots and Systems, 2009. IROS 2009. IEEE/RSJ International Conference on, Oct. 2009, accepted, To Appear.

[18] S. E. Webster, O. Pizarro, and H. Singh, "Photomosaics in underwater archaeology,” INA Quartlery, vol. 28, no. 3, pp. 22-26, 2001.

[19] L. L. Whitcomb, M. V. Jakuba, J. C. Kinsey, S. C. Martin, S. E. Webster, J. C. Howland, C. L. Taylor, D. Gomez-Ibanez, and D. R. Yoerger, "Navigation and control of the Nereus hybrid underwater vehicle for global ocean science to $11,000 \mathrm{~m}$ depth: Preliminary results," in Proc. 14th Yale Workshop on Apative and Learning Systems, Yale University, June 2008. 